Voix et Images

\title{
Le dictionnaire des oeuvres littéraires du Québec : l’événement de la décennie
}

\section{André Vanasse}

Volume 8, numéro 3, printemps 1983

Jacques Ferron

URI : https://id.erudit.org/iderudit/200408ar

DOI : https://doi.org/10.7202/200408ar

Aller au sommaire du numéro

Éditeur(s)

Université du Québec à Montréal

ISSN

0318-9201 (imprimé)

1705-933X (numérique)

Découvrir la revue

Citer ce compte rendu

Vanasse, A. (1983). Compte rendu de [Le dictionnaire des oeuvres littéraires du Québec : l'événement de la décennie]. Voix et Images, 8(3), 515-517.

https://doi.org/10.7202/200408ar d'utilisation que vous pouvez consulter en ligne.

https://apropos.erudit.org/fr/usagers/politique-dutilisation/ 


\title{
Le dictionnaire des oeuvres littéraires du Québec: l'événement de la décennie
}

\author{
par André Vanasse, Université du Québec à Montréal
}

L'automne dernier, paraissait, sous une couverture qui reproduit une encre admirable de Roland Giguère, le troisième tome du Dictionnaire des oeuvres littéraires du Québec (1940 à 1959)'.

Pour tous les chercheurs, cette parution etait attendue: le Dictionnaire est sans conteste l'événement de la décennie. Le travail accompli par l'équipe du DOLQ, qui réunit, sous la direction de Maurice Lemire, les professeurs Gilles Dorion, André Gaulin, Alonzo Leblanc et les chargés de recherche Aurélien Boivin, Roger Chamberland, Kenneth Landry et Lucie Robert, se révèle tout à fait a la hauteur de notre attente.

Imposant (il totalise 1252 pages), relié avec soin, convenablement illustré (quoique j'aurais apprécié qu'il le soit plus), typographiquement impeccable, le Dictionnaire des oeuvres contient une somme inépuisable de renseignements.

Pour s'en convaincre, qu'il suffise de rappeler les principales rubriques de la table des matières. $D^{\prime}$ abord une longue introduction (près de cinquante pages) suffisamment étoffee pour rendre compte des conditions de l'époque (bien qu'il faille reconnaître que les introductions des deux premiers tomes étaient mieux réussies et plus percutantes). Ensuite une chronologie des événements marquants au Québec et au Canada français, ceux-ci étant mis en relation avec ceux du "monde" et de "I'Amérique anglo-saxonne".

L'essentiel du Dictionnaire porte, bien sûr, sur les entrées. Elles débutent avec Aaron d'Yves Thériault et se terminent avec Zone de Marcel Dubé (comme quoi le hasard fait bien les choses!). On voudra m'excuser de ne pas les avoir calculées (Gérard Bessette, arithmomane avoú, le fera sans doute un jour) mais ce qui paraît certain c'est que cet inventaire est sans conteste le plus exhaustif jamais publié à ce jour. De Constantin-Weyer Ve Bar de Sain Miguel, Paris, Ed. R. Simon, 1946) en passant par Edgar Morin (Puce, Québec, les éditions du Quartier latin, 1949) sans oublier Roland Giguére LAdorable femme des neiges podme..., illustré par l'auteur, Châteaunoir, Aixen-Provence. Erta, 1959, 12 feuillets sous étuil tout y est répertorié y compris la littéra- 
ture radiophonique (Rue principale d'Edouard Beaudry, Vie de famille de Henry Deyglun) du moins celle qui fut publiée. Une seule ombre au tableau: l'absence de la littérature populaire, plus particulièrement des romans imprimés en fascicules Ves Aventures étranges de l'agent IXE 13, I'as des espions canadiens; les Aventures policières d'Albert Brien etc.). Ainsi le nom de Pierre Daignault (ou Pierre Saurell ne figure nulle part. Ce trou est tout de même malheureux quand on songe que c'est gràce à ce genre de publications (les romans en fascicules et les radio-romans ont été les deux principales "littératures alimentaires" de l'époquel qu'Yves Thériault et Michel Van Schendel, pour ne nommer que deux cas extrêmes, ont pu survivre au cours de cette période de vaches maigres pour les écrivains.

Quoi qu'il en soit, ce répertoire des auteurs québécois prouve à l'évidence que nos critiques littéraires se posaient d'inutiles questions quand ils s'interrogeaient sur l'existence de notre littérature. Le DOLQ cite quelques titres dans son introduction: "Pourquoi nous n'avons pas de littérature" de Jean-Guy Blain ou "Unè solide littéra ture est-elle viable au Canada français?" de Gilles Marcotte. Or il est bien évident, devant la masse des publications, que ces interrogations ne peuvent concerner que la qualité de nos oeuvres. L'ombre de la France planait encore sur nos têtes. De fait elle devait couvrir encore notre paysage jusqu'en 1960, c'est-à-dire bien au-delà de l'admissible.

Pourtant il existe, grâce surtout aux journaux, une véritable vie littéraire au Québec. A ce sujet, il faut féliciter le DOLQ pour le travail remarquable qu'il a accompli en dépouillant systérnatiquement les revues et journaux de l'époque. A la fin de chaque titre, on a dressé des bibliographies vraiment exhaustives. Celle du Survenant, par exemple, contient près de cent vingt-cinq références.

Ainsi les chercheurs et thésards trouveront dans ce dictionnaire des informa tions bibliographiques qui pourront leur épargner bien des heures de recherche. D'autant plus qu'à cette bibliographie ponctuelle s'ajoute une bibliographie générale qui contient: I- l'ensemble des oeuvres publiées durant la période concernée; II- les instruments de travail et ouvrages généraux de référence; lil- les études à consulter comprenant: A- les volumes et chapitres de volumes; B- les thèses; C- les articles de périodiques.

A mon avis, le Dictionnaire des oeuvres litteraires du Quebec se présente comme le plus exhaustif jusqu'a ce jour. II fait la somme et complète divers volumes de synthèse ou de références édités dans le passé. Je pense aux ouvrages, toujours utiles ne serait-ce qu'à cause des articles de fond qu'ils contiennent, lancés par le "Centre de recherche en civilisation canadienne-française" de l'Université d'Ottawa, plus précisément aux trois tomes sur le roman, la poésié et le théatre de même qu'à cette importante Bibliographie de la critique de la littérature québécoise dans les revues des XIXe et XXe siècles de Pierre Cạntin, Normand Harrington et Jean-Paul Hudon, (Ottawa, 1979, 5 tomes, $1254 \mathrm{p}$. l qui a súrement facilité le travail de l'équipe du $D O L Q$ pour ce qui concerne les revues (les journaux étant exclus de cette compilation).

Le Dictionnaire des oeuvres littéraires du Québec me paraît donc une réussite à tous les points de vue même si la formule des comptes rendus se révèle, au fil d'une lecture continue, un peu trop coercitive dans la mesure où elle oblige les collabora teurs à se conformer à un modèle descriptif qui freine grandement leur liberté (cela. est évident tout particulièrement pour les courts textest. Mais c'est le prix à payer pour 
faire de ce dictionnaire un instrument qui soit clair et à la porté de tous, une somme sans doute un peu trop anonyme mais monumentale et qui réhabilite aux yeux de tous les Québécois une littérature qu'on a trop souvent prétendue inexistante.

1. Dictionnaire des oeuvres littéraires du Québec, tome III, 1940-1959, sous la direction de Maurice Lemire, avec la collaboration de Gilles Dorion, André Gaulin, Alonzo LeBlanc et Aurélien Boivin. Roger Chamberland, Kenneth Landry et Lucie Robert, Montr6al, Fides, (1982), XCII,1252 pages. 